\title{
Factors Influencing Prognosis in the Endoscopic Extraction of Foreign Bodies in Kashmiri Population
}

\author{
M. S. Sheikh1*, S. Gul Afshan'2, Meelad Mohammad Sheikh³ , S. Bunafsha ${ }^{4}$ \\ ${ }^{1}$ Government Medical Collage, R/o Gulshan Nagar, Sector-C, Srinagar, India \\ ${ }^{2}$ Women's Medical Collage Hospital, Dhaka, Bangladesh \\ ${ }^{3}$ Government Dhaka Medical College, Dhaka, Bangladesh \\ ${ }^{4}$ Department of ENT, Head and Neck Surgery, Government Medical College, Srinagar, India \\ Email: *mohammadsubhan2280@gmail.com
}

How to cite this paper: Sheikh, M.S., Afshan, S.G., Sheikh, M.M. and Bunafsha, S. (2019) Factors Influencing Prognosis in the Endoscopic Extraction of Foreign Bodies in Kashmiri Population. International Journal of Otolaryngology and Head \& Neck Surgery, 8, 32-48.

https://doi.org/10.4236/ijohns.2019.81005

Received: November 9, 2018

Accepted: December 31, 2018

Published: January 3, 2019

Copyright (c) 2019 by author(s) and Scientific Research Publishing Inc. This work is licensed under the Creative Commons Attribution International License (CC BY 4.0).

http://creativecommons.org/licenses/by/4.0/

\begin{abstract}
An updated approach in the management of 50 patients with foreign body inhalation is presented. Certain risk factors that lead to complications and mortality due to endoscopic extraction of foreign bodies and thus determine prognosis were identified. Remedial measures to reduce morbidity and mortality due to bronchoscopic removal of foreign bodies are suggested. Fifty patients of suspected foreign body inhalation presented to a Unit of the Department of ENT, Head and Neck Surgery of Government Medical College associated SMHS Hospital Srinagar, Kashmir from March 2007 to June 2017. Of these, 49 patients were subjected to rigid tube bronchoscopy for removal of the aspirated foreign bodies and one coughed out the foreign body spontaneously during admission for bronchoscopy. History of foreign body inhalation was positive in $90 \%$ of patients and remaining was mostly referred from Paediatric Units with un-resolving collapse-consolidation of the lung. Whereas plain radiography of the chest and the soft tissues of neck were the primary imaging modality used in this study to detect the inhaled foreign bodies or their effects there are reports of virtual bronchoscopy being done with a multidetector computed tomography scanner in 3D image generation from axial cuts of the internal walls of the tracheobronchial tree in the management of patients suspected with foreign body aspiration. Bronchoscopy is a difficult and potentially hazardous procedure in the infant and young child. Telescopes and telescopic forceps were used during bronchoscopy to facilitate extraction of a foreign body inhaled. The type of a foreign body, site of its enlodgement and the complications encountered during its extraction were noted. During bronchoscopy the patients were connected to an ECG monitor
\end{abstract}


and a pulse oximeter. $80 \%$ of the patients with foreign body inhalation were children in the age group of 0 - 5 years. There was a definite history of choking over the foreign body in $88 \%$ of the patients leading to acute respiratory distress in $46 \%$. Cough alone or along with other symptoms occurred in most of the patients (96\%). Persistent fever with respiratory symptoms unresponsive to treatment occurred in $38 \%$ of the patients with or without a positive history of foreign body inhalation. Right main bronchus was the commonest site of enlodgement of foreign body. In the present study, bean and peanut were the commonest types of foreign bodies inhaled (34\%). Radiological findings in these patients include atelectasis with or without pneumonitis in $46.65 \%$ of the patients, normal chest/soft tissues of the neck in $24.45 \%$, obstructive emphysema on the affected side in $24.45 \%$, foreign body seen in the respiratory tract in $8.90 \%$ and bronchopneumonia in $2.22 \%$. Complications associated with the endoscopic extraction of foreign bodies and the risk factors that lead to complications and mortality in patients with aspirated foreign bodies were identified in this study and the measures to reduce these complications and mortality rate to very low levels were suggested. Transient hypoxia, hypoxic bradycardia, transient cardiac arrest, bronchial perforation and death, laryngospasm, bronchospasm, subglottic oedema, reflex bradycardia and pneumothorax were among the few complications which occurred with the rigid endoscopic extraction of foreign bodies in the present study. Among the risk factors associated with the complications were prolonged bronchoscopy, semi-blind procedure, a vegetable foreign body, improper size and positioning of a bronchoscope and some other important factors which are detailed in the text of this paper to follow. Remedial measures on the basis of complications and the risk factors are suggested so as to decrease the morbidity and mortality due to endoscopic extraction of foreign bodies inhaled into the tracheobronchial tree.

\section{Keywords}

Inhaled Foreign Bodies, Collapse-Consolidation, Obstructive Emphysema, Virtual Bronchoscopy, Rigid Tube Bronchoscopy, Hypoxic Bradycardia, Bronchospasm, Subglottic Oedema, Pneumothorax, Tracheostomy, Prognosis

\section{Introduction}

Foreign bodies inhaled into the larynx and trachea can cause total respiratory obstruction and death within a few minutes if help is not ready to hand. Two engravings in Egypt record the performance of tracheostomy by Egyptians about five thousand and six hundred years ago [1]. Boo Ali Ibne-Sina (Avicenna) quoted by Bradley [2], in the tenth century A. D. advocated tracheostomy for otherwise hopeless cases of the airway obstruction. Foreign bodies inhaled into the bronchus cause atelectasis with or without pneumonia (Figure 1) or obstructive emphysema (Figure 2) in most of the patients and if neglected can lead 


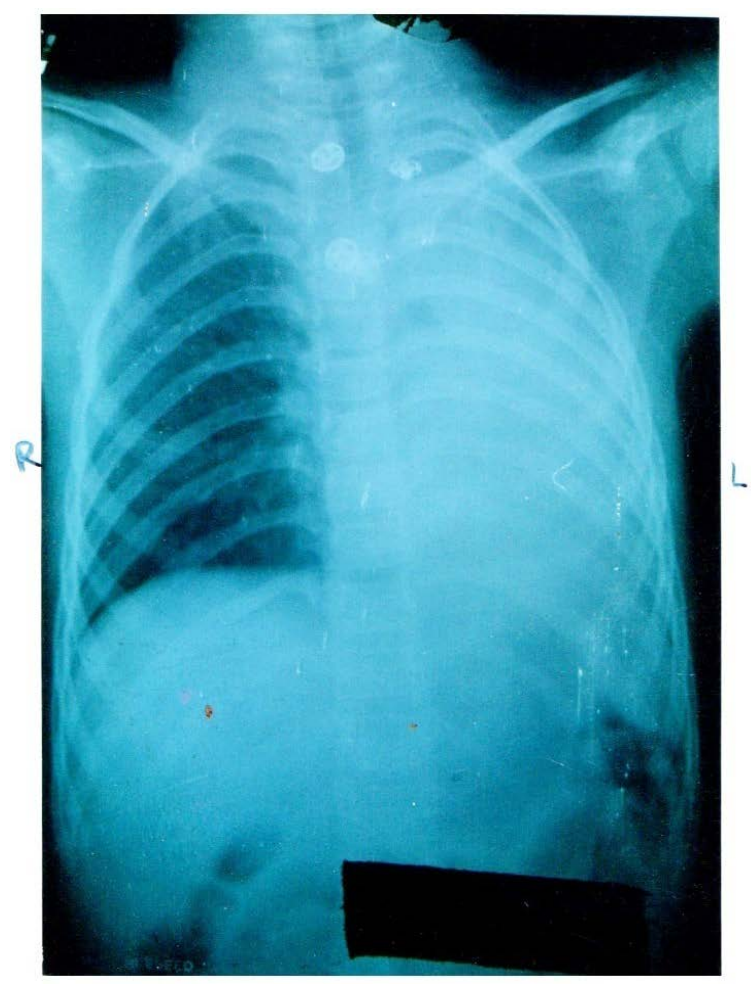

Figure 1. Foreign body in left main bronchus causing atelectasis with pneumonia.

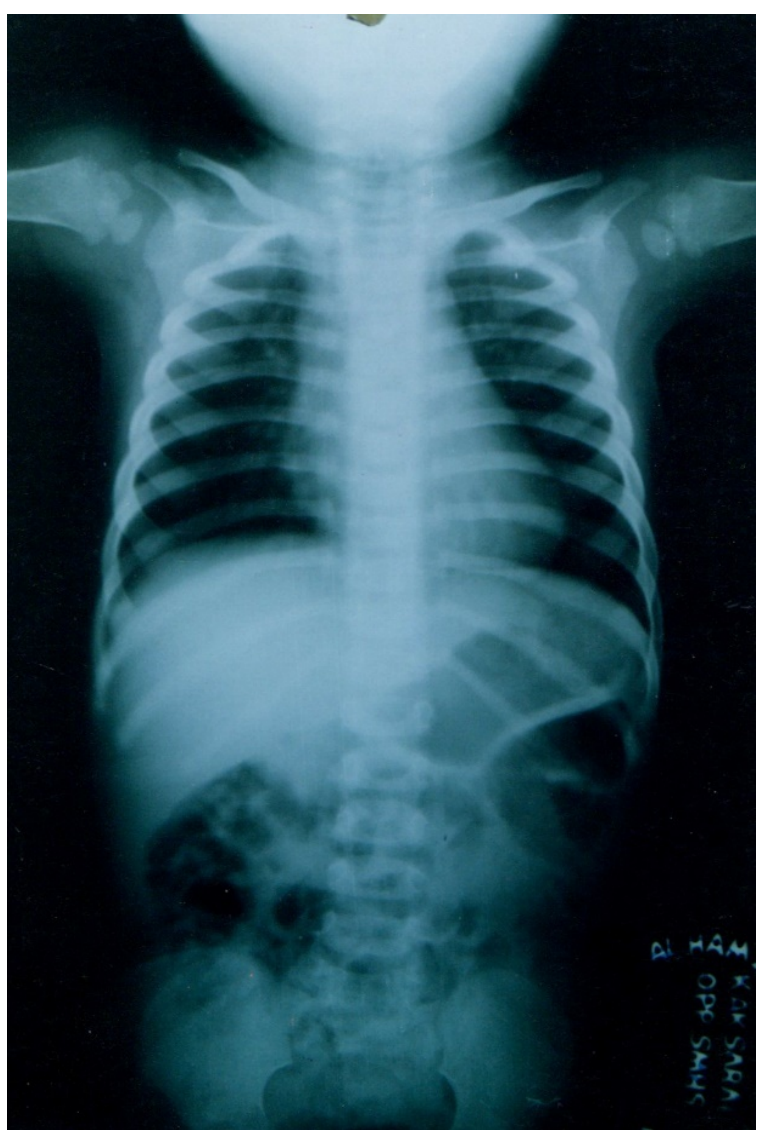

Figure 2. Obstructive emphysema right lung base due to foreign body impaction. 
to formation of lung abscess. In most cases of inhaled foreign body there is a definite history of choking followed by paroxysmal coughing which later subsides. Modern techniques of endoscopic removal of bronchial foreign bodies were the result of the advances made in early part of the twentieth century by Chevalier Jackson who succeeded in reducing mortality from the procedure significantly. The advent of ventilating bronchoscope, improvement in the illumination and magnification provided by Hopkins' rod lens system, fibre optic bronchoscopy, virtual bronchoscopy [3] and advances in anaesthesia have markedly reduced mortality rate due to endoscopic extraction of inhaled foreign bodies.

\section{Materials and Methods}

This study is a prospective randomized clinical trial in which fifty patients of suspected foreign body inhalation who presented to the Department of ENT, Head and Neck Surgery of the Govt. Medical College associated SMHS Hospital Srinagar, Kashmir directly or through referral from other hospitals in the State over a period of 5 years from March 2007 to June 2017 were subjected to rigid tube bronchoscopy for removal of aspirated foreign bodies. Majority of the patients in this series were children. The youngest patient was 6 months old and the oldest was of 22 years of age. Infants or children with foreign bodies impacted in the larynx or in the trachea who presented with stridor, choking and coughing were subjected to emergency tracheostomy before bronchoscopy. Falling oxygen saturation after a prolonged bronchoscopy is usually indicative of subglottic oedema, bronchospasm or pneumothorax, and may also need airway assistance. Radiography of the chest before bronchoscopy was done in 46 patients (92\%) and was repeated after the procedure in all of the patients who survived. The distribution of foreign bodies at various sites in the respiratory tract is depicted under observations. The type of foreign body and the complications encountered during the procedure were noted. Brochoscopes used for children relating the size of the instrument to the age of the child are tabulated below (Table 1). Telescopes, telescopic forceps, and fibre optic bronchoscope can be passed along the metallic rigid tube bronchoscope to facilitate extraction of a foreign body. There is a wide selection of foreign body extraction forceps available for every individual type of a foreign body. During the procedure the patients' heart rate was monitored and the oxygen saturation level continuously perceived with an oximeter.

\section{Observations}

Age and sex distribution: Age of the patients with foreign body inhalation ranged from 6 months to 22 years, including five infants with age below 1 year. The average age of the patients was 3 years and 4 months. $80 \%$ of the patients belonged to the age group of 0 - 5 years. $74 \%$ of the patients were male and $26 \%$ were female. Table 2 depicts the age and sex distribution in 50 patients with foreign body inhalation. 
Table 1. Size of bronchoscope with respect to age of the patient.

\begin{tabular}{ccc}
\hline Size marked on bronchoscope (I.D in mm) & External diameter (in mm) & Age range \\
\hline 2.5 & 4 & Premature/Neonate \\
3 & 5 & 4 weeks - 3 months \\
3.5 & 5.7 & 4 - 12 months \\
4 & 7 & 12 - 36 months \\
5 & 7.8 & 3 - 9 years \\
6 & 8.2 & Over 9 years \\
\hline
\end{tabular}

Table 2. Age and Sex distribution in 50 patients with foreign body inhalation.

\begin{tabular}{cccc}
\hline Age group (years) & No. of patients (\%) & Male (\%) & Female (\%) \\
\hline $0-5$ & $40(80.00 \%)$ & $30(60.00 \%)$ & $10(20.00 \%)$ \\
$5-10$ & $8(16.00 \%)$ & $6(12.00 \%)$ & $2(4.00 \%)$ \\
$10-15$ & $1(2.00 \%)$ & $0(0.00 \%)$ & $1(2.00 \%)$ \\
$15-20$ & $0(0.00 \%)$ & $0(0.00 \%)$ & $0(0.00 \%)$ \\
$20-30$ & $1(2.00 \%)$ & $1(2.00 \%)$ & $0(0.00 \%)$ \\
Total & $\mathbf{5 0 ( 1 0 . 0 0 \% )}$ & $\mathbf{3 7}(74.00 \%)$ & $13(26.00 \%)$ \\
\hline
\end{tabular}

Clinical features: There was history of choking over the foreign body in $88 \%$ of the patients leading to acute respiratory distress in $46 \%$. Cough alone or along with other symptoms occurred in most of the patients (96\%). Persistent fever with respiratory symptoms un-responsive to treatment occurred in $38 \%$ of the patients with or without a positive history of foreign body inhalation; and a loud wheeze in the chest was audible in $16 \%$. Loud whistling sound was heard from a plastic whistle impacted in the right principal bronchus in one patient (2\%). History of foreign body inhalation was positive in most of the patients $(90 \%)$ and the remaining were mostly referred from the Paediatric Units of other hospitals with unresolving collapse-consolidation of the lung. Duration of enlodgement of foreign bodies ranged from 1 hour to 2 months. Decreased breath sounds on the affected side were the most common examination finding (78\%).

Radiological signs: Of 50 patients with the history of inhalation of foreign body radiography of chest/soft tissues of neck was done in 45 patients and in the remaining 5 radiograph could not be obtained because of urgency of foreign body removal. Radiological signs due to the inhalation of foreign bodies in the present study included atelectasis of lung with or without consolidation in $46.67 \%$, normal chest/soft tissues of neck in $24.44 \%$, obstructive emphysema in $17.78 \%$, foreign body seen in the respiratory tract in $8.89 \%$ (Figure 3 and Figure 4 ) and bronchopneumonia in $2.22 \%$. Table 3 depicts these results.

Treatment: Larngeal foreign bodies in this study were successfully extracted by emergency tracheostomy followed by endoscopy in $6 \%$ of the total number of patients, direct laryngoscopy with Mackintosh laryngoscope in 4\%, and rigid 


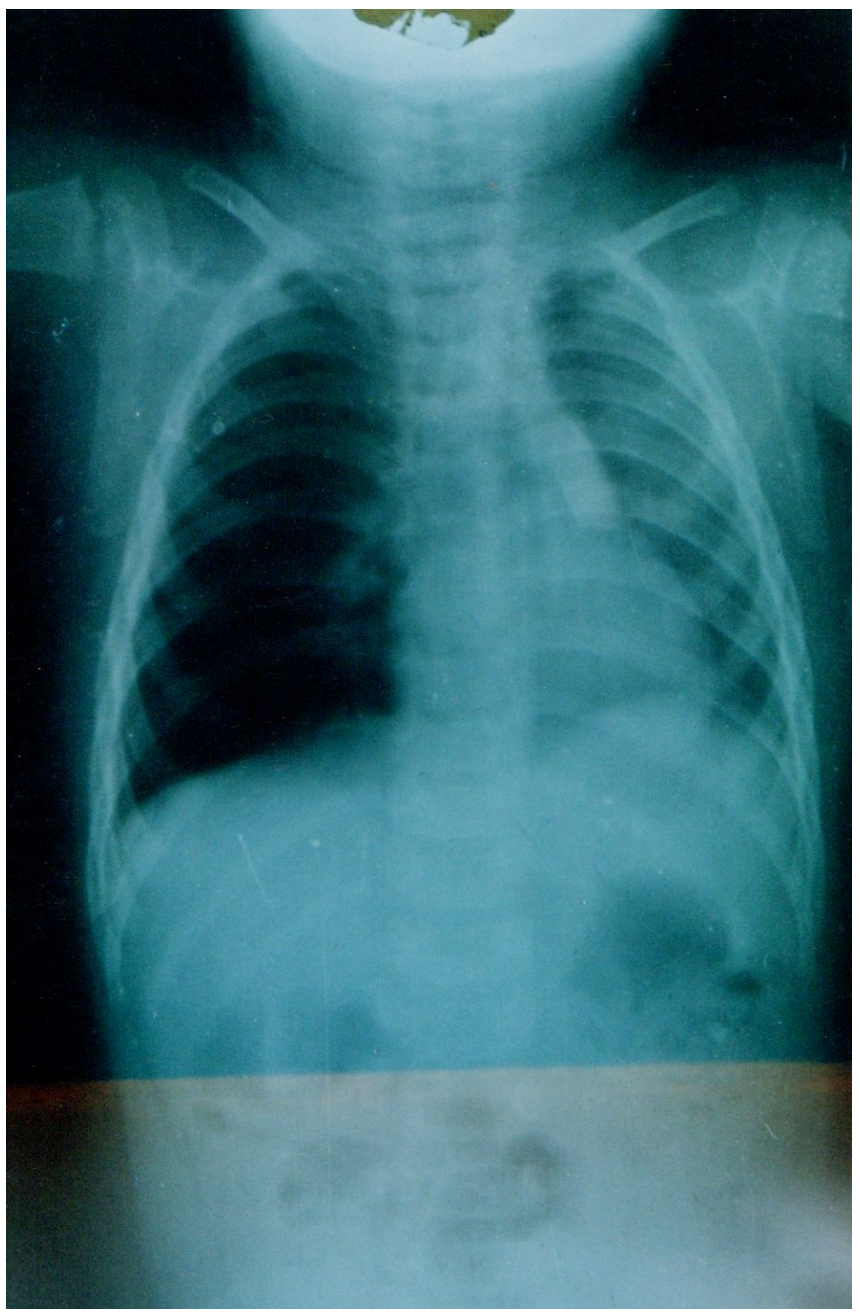

Figure 3. A plastic whistle seen in left main bronchus with atelectasis of lung.

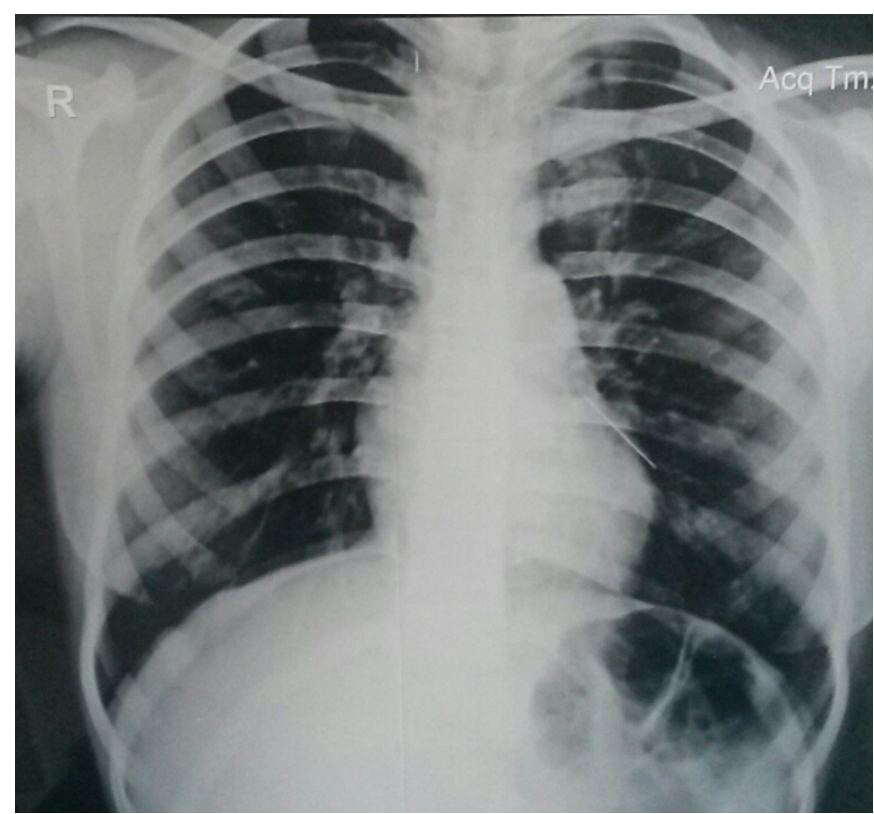

Figure 4. A scarf pin seen in left main bronchus. 
Table 3. Radiological Signs in 45 patients with foreign body inhalation.

\begin{tabular}{ccc}
\hline Radiological sign & No. of Patients & \% age \\
\hline Atelectasis of lung with or without consolidation & 21 & 46.65 \\
Normal chest/Soft tissues of neck & 11 & 24.45 \\
Obstructive emphysema & 8 & 17.78 \\
Foreign body seen & 4 & 8.90 \\
Bronchopneumonia & 1 & 2.22 \\
Total & 45 & 100 \\
\hline
\end{tabular}

tube bronchoscopy without preliminary tracheostomy in $2 \%$ whereas a laryngeal foreign body was spontaneously coughed out by one patient (2\%). Tracheal and bronchial foreign bodies were removed using different sizes of the metallic ventilation bronchoscope with respect to the age of the patient.

Type of the foreign body: Children can inhale whatever foreign material comes in their way. Of vegetable foreign bodies $80 \%$ of the patients inhaled beans, peanut and maize grains. Of inert foreign bodies plastic whistles and pen caps were commonly aspirated foreign bodies (18\% of the patients). Table 4 shows the type of foreign body inhaled in 50 patients.

Location of foreign body in the respiratory tract: Right main bronchus was the commonest site of enlodgement of foreign body ( $46 \%$ of the cases) in this study followed by left main bronchus (22\%), trachea (12\%), subglottis (8\%), carina $(4 \%)$, glottis (2\%), glottis to subglottis (2\%), all sites of respiratory tract (2\%) and undetermined (2\%). Table 5 depicts the site of foreign body enlodgement in 50 patients.

Complications and risk factors: Complications associated with the endoscopic extraction of inhaled foreign bodies can be serious (Figure 5) and many occasionally prove fatal. Mortality rate due to the rigid tube endoscopic removal of foreign bodies in this study was $8 \%$. Certain risk factors that lead to complications were identified and included the age below 1 year, a vegetable foreign body, prolonged bronchoscopy beyond 20 minutes, traumatic procedure by an occasional less experienced endoscopist in the learning phase, occasional less skilled anaesthetist, improper instrumentation and delayed patient presentation or delayed referral when pneumonitis has already supervened. Complications and the associated risk factor due to the rigid tube bronchoscopic extraction of inhaled foreign bodies in forty nine patients are enlisted in Table 6 .

\section{Discussion}

Foreign body inhalation is a major cause of accidental death during childhood [4]. $90 \%$ of the patients in the present series were children below 5 years; and this age incidence is comparable to many other studies [5] [6] [7] [8]. Elhassani et al. [9], however, report in Iraq foreign body inhalation is more frequently seen in infants. The factors contributing to the inhalation of a foreign body in 


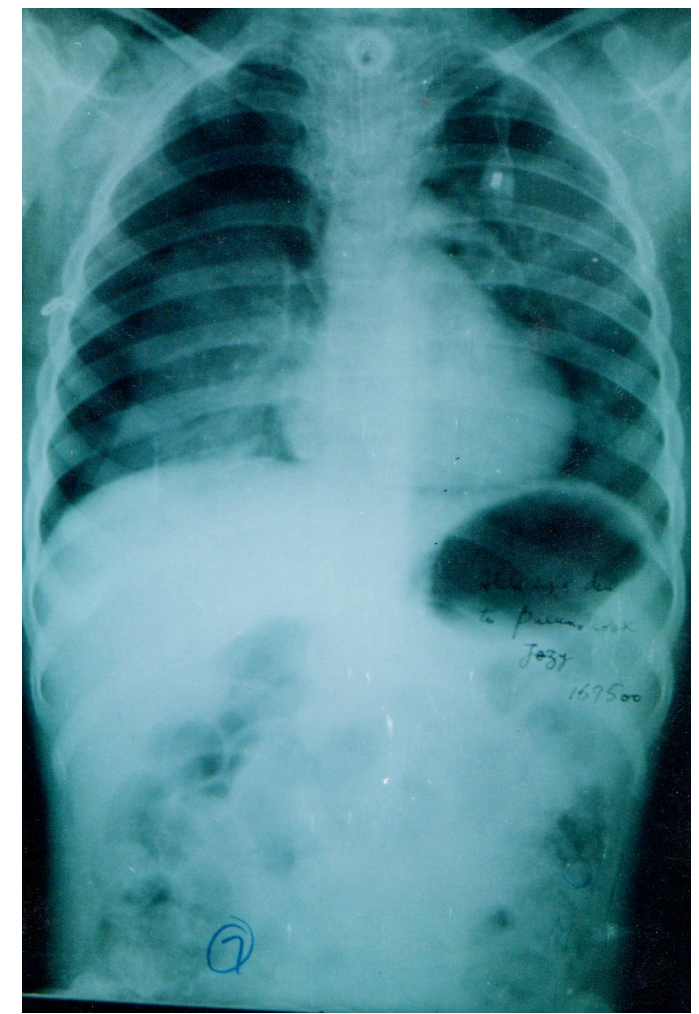

Figure 5. Right-sided pneumothorax complicating tracheostomy in a patient with subglottic plastic pen-cap impaction.

Table 4. Showing the type of foreign body inhaled in 50 patients.

\begin{tabular}{cccccc}
\hline \multicolumn{4}{c}{ Organic (reactive) foreign body } & \multicolumn{2}{c}{ Inert (non-reactive) foreign body } \\
\hline Type & $\begin{array}{c}\text { No. of } \\
\text { patients }\end{array}$ & $\begin{array}{c}\% \text { (of the } \\
\text { total cases) }\end{array}$ & Type & $\begin{array}{c}\text { No. of } \\
\text { patients }\end{array}$ & $\begin{array}{c}\% \text { (of the } \\
\text { total cases) }\end{array}$ \\
Bean & 12 & 24 & Plastic whistle & 5 & 10 \\
Peanut & 5 & 10 & Plastic pen cap & 4 & 8 \\
Maize grain & 3 & 6 & Pill cover & 2 & 4 \\
Almond shell & 3 & 6 & Scarf needle & 2 & 4 \\
A piece of vegetable & 2 & 4 & Egg shell & 1 & 2 \\
Cherry seed & 1 & 2 & Metallic bead & 1 & 2 \\
Cover of peanut & 1 & 2 & & & \\
Pumpkin seed & 1 & 2 & & \\
A piece of walnut & 1 & 2 & & \\
A piece of waternut & 1 & 2 & & \\
Pea seed & 1 & 2 & & \\
Decomposed paper & 1 & 2 & & \\
A piece of cashew nut & 1 & 2 & & \\
A piece of coconut & 1 & 2 & & \\
Bone piece & 1 & 2 & & \\
\hline
\end{tabular}


Table 5. Site of foreign body enlodgement in the respiratory tract in 50 patients.

\begin{tabular}{ccc}
\hline Site & No. of patients & $\%$ \\
\hline Right main bronchus & 23 & 46 \\
Left main bronchus & 11 & 22 \\
Trachea & 6 & 12 \\
Subglottis & 4 & 8 \\
Carina & 2 & 4 \\
Glottis & 1 & 2 \\
Glottis to subglottis & 1 & 2 \\
All sites & 1 & 2 \\
Undetermined (spontaneously coughed out) & 1 & 100 \\
Total & 50 & \\
\hline
\end{tabular}

Table 6. Complications associated with the bronchoscopic extraction of foreign bodies in 49 patients.

\begin{tabular}{|c|c|c|c|c|c|}
\hline Complication & $\begin{array}{c}\text { No. } o \\
\text { patients }\end{array}$ & $\begin{array}{l}\% \text { of the total } \\
\text { bronchoscopies/D.L }\end{array}$ & Associated risk factor/factors & $\begin{array}{c}\text { No. of } \\
\text { patients }\end{array}$ & $\begin{array}{c}\% \text { of the total } \\
\text { bronchoscopies/D.L }\end{array}$ \\
\hline \multirow{3}{*}{ Transient hypoxia } & \multirow{3}{*}{3} & \multirow{3}{*}{6.12} & 1) Age below 1 year & 1 & 2.04 \\
\hline & & & $\begin{array}{l}\text { 2) Pre-existing pneumonia due to } \\
\text { delayed presentation/referral in } \\
\text { an infant (below } 1 \text { year) }\end{array}$ & 1 & 2.04 \\
\hline & & & $\begin{array}{l}\text { 3) Improper size and positioning } \\
\text { of a bronchoscope }\end{array}$ & 1 & 2.04 \\
\hline & & & 1) Age below 1 year & 1 & 2.04 \\
\hline Hypoxic bradycardia & 2 & 4.08 & $\begin{array}{l}\text { 2) Lighter plane of anaesthesial/less } \\
\text { skilled anaesthetist) }\end{array}$ & 1 & 2.04 \\
\hline \multirow{2}{*}{ Transient cardiac arrest } & \multirow{2}{*}{2} & \multirow{2}{*}{4.08} & $\begin{array}{l}\text { 1) Vegetable foreign body } \\
\text { necessitating prolonged bronchoscopy } \\
\text { in an infant below } 1 \text { year }\end{array}$ & 1 & 2.04 \\
\hline & & & $\begin{array}{l}\text { 2) Semiblind technique without } \\
\text { using a telescope or telescopic forceps } \\
\text { (thus prolonging the procedure) }\end{array}$ & 1 & 2.04 \\
\hline Cardiac arrest and death & 1 & 2.04 & $\begin{array}{l}\text { Vegetable foreign body } \\
\text { necessitating prolonged bronchoscopy }\end{array}$ & 1 & 2.04 \\
\hline Bronchial perforation and death & 2 & 4.08 & Less skilled bronchoscopist & 2 & 4.08 \\
\hline Reflex bradycardia & 1 & 2.04 & Age below 1 year & 1 & 2.04 \\
\hline Bronchospasm & 1 & 2.04 & $\begin{array}{l}\text { Delayed referral with pre existing } \\
\text { pneumonia }\end{array}$ & 1 & 2.04 \\
\hline $\begin{array}{l}\text { Misdirection of bronchoscope } \\
\text { into oesophagus }\end{array}$ & 1 & 2.04 & Less skilled bronchoscopist & 1 & 2.04 \\
\hline Laryngospasm & 1 & 2.04 & $\begin{array}{l}\text { Less skilled bronchoscopist with } \\
\text { laryngeal trauma }\end{array}$ & 1 & 2.04 \\
\hline Subglottic oedema & 1 & 2.04 & $\begin{array}{l}\text { Vegetable foreign body necessitating } \\
\text { prolonged bronchscopy }\end{array}$ & 1 & 2.04 \\
\hline Pneumothorax & 1 & 2.04 & $\begin{array}{l}\text { Vegetable foreign body necessitating } \\
\text { prolonged bronchloscopy }\end{array}$ & 1 & 2.04 \\
\hline Surgical emphysema neck, chest & 1 & 2.04 & $\begin{array}{l}\text { Less skilled bronchoscopist } \\
\text { with a traumatic procedure }\end{array}$ & 1 & 2.04 \\
\hline Cerebral anoxia and death & 1 & 2.04 & $\begin{array}{l}\text { Vegetable foreign body necessitating } \\
\text { a prolonged procedure }\end{array}$ & 1 & 2.04 \\
\hline Paralytic ileus & 1 & 2.04 & $\begin{array}{l}\text { Vegetable foreign body necessitating } \\
\text { a prolonged procedure forced } \\
\text { ventilation for hypoxia (with mask) }\end{array}$ & 1 & 2.04 \\
\hline
\end{tabular}


younger children more commonly than in adults seem to be the anatomic relations of the larynx in children which is high up and more posteriorly placed in the neck; difficulties in chewing due to the lack of molars; their tendency to put almost every object in mouth for exploring its texture and taste; shouting, crying and playing while eating which open the laryngeal inlet reflexly; recurrent upper respiratory infections, coughing and mouth breathing causing sharp intake of breath which follows a cough; and finally the poorly co-ordinated swallowing reflex. Male to female ratio in our study was nearly 3:1. In the studies made by Rothman and Boeckman [10] and O'Neill, Holcomb and Neblett [11] boys were more likely to inhale foreign bodies than girls in a ratio of 2:1. In most cases of the inhaled foreign body there is a history of choking which may lead to acute respiratory distress. Anissa Berraies et al. [12] report that choking is the most specific symptom with a good sensitivity for the diagnosis of foreign body aspiration. Cough alone or along with other symptoms occurred in most of the patients in the present study. After the initial episode of choking and coughing the respiratory mucosal cough reflex dulls and the cough ceases which may lead to delay in diagnosis with different clinical presentations including persistent fever with respiratory symptoms unresponsive to treatment (accounting for $38 \%$ of the patients in this study), a loud wheeze in the chest (16\%). History of foreign body inhalation was positive in $90 \%$ of the patients in this series and the remaining was referred from other paediatric hospitals with unresolving collapse-consolidation of the lung. Duration of enlodgement of the foreign body was one hour to 2 months. Kamaljit Kour (2002) observed a diagnostic triad of cough, wheezing and decreased $b$ reath sounds on the affected side of the chest in patients with foreign body inhalation. In the series of Mahyar and Torlan (2008) with foreign body aspiration clinical history of foreign body inhalation was observed in $57.4 \%$, and included cough in $90 \%$, wheeze in $39.6 \%$, and decreased pulmonary sounds in $36.6 \%$. Asif et al. [13] report choking to be the most common symptom and decreased air entry on auscultation on the affected side to be the typical finding of an inhaled foreign body. Nazar B. Elhassani (1978) reports nearly $50 \%$ of the children with foreign body inhalation were seen within 24 hours of the incident and most of these presented with cough and wheezing respiration.

The most common radiological sign in patients with foreign body inhalation in the present study were atelectasis of the lung with or without consolidation (46.6\%) followed by normal chest/soft tissues of neck in $24.44 \%$, obstructive emphysema in $17.78 \%$, foreign body seen in the respiratory tract in $8.89 \%$ and bronchopneumonia in $2.22 \%$. According to the study of Jennis Dennilidis et al. [14] the most common radiological finding in these patients was the obstructive emphysema corresponding to the bronchus containing the foreign body and was associated with mediastinal shift to the opposite side. The other radiological signs observed by these authors were atelectasis due to complete bronchial obstruction; pneumonia; bronchopneumonia; and finally the visibility of a foreign body in the x-ray film. In the Tunisian study of Anissa Berraies (2015) 18\% of 
the patients with FBA had normal radiography whereas air-trapping was observed in $60 \%$ of cases mainly in the early diagnosed forms. In the later diagnosed patients in their study atelectasis and pneumonia were more often detected. Although spontaneous expulsion of the inhaled foreign body can occur ( $2 \%$ in the present series) rigid tube bronchoscopic removal of the inhaled foreign bodies is the treatment of choice [15]. Careful examination of the instrument before use is important to reduce the complications and to shorten the duration of the procedure, which is directly proportional to the morbidity and mortality rates. Good interaction is necessary between the endoscopist and the anaesthesiologist. All types of foreign bodies in the present study could be removed with a ventilation bronchoscope; however, thoracotomy has been reported as a method of removing inhaled foreign bodies such as nail, bead or bone that may not be grasped with an endoscopic forceps [16]. Fibreoptic bronchoscope can remove the inhaled foreign bodies in a good percentile of patients (Cananan 1978). Virtual bronchoscopy as a non-invasive imaging method has potential for use in detecting foreign bodies in the airways of children and can even preclude the need to submit these children to rigid bronchoscopy in the absence of a foreign body [17]. The type of foreign body inhaled usually depends on geographical regions of the world. Bean was the commonest foreign body inhaled in this study. Children have easy access to beans as these are sundried after harvesting in rural areas of Kashmir. Watermelon seeds are the most frequently found inhaled foreign bodies in Turkey and Middle East as reported respectively by Aytac et al. (1976) and El-Hassani (1978) because in summers this fruit is commonly available and cheaper one in these areas. Nutty substances were found to be inhaled commonly in winters in their series. Dry pumpkin seeds are commonly inhaled in Greece because of Greek habit of eating them. Right main bronchus was the commonest site of enlodgement of the foreign body in the present study (50\%) followed by left main bronchus (32\%), trachea (10\%), carina (4\%), subglottis (2\%), and glottis (2\%). Many studies report right main bronchus to be the most common site of enlodgement of foreign body citing the anatomy as a possible reason as it is a direct continuation of trachea (Elhassani 1978) which, however, has not been confirmed by others [18]. The latter found equal incidence of foreign bodies in the left or right main bronchus whereas in Jennis series of 90 cases the site of foreign body was predominantly found in left main bronchus in children and right main bronchus in adults giving explanation that the children usually inhale while lying down and hold the foreign body with the right hand. They comment, in this position the angle between the trachea and the left bronchus is somewhat straightened. The anatomical considerations that the right main bronchus is nearly a direct continuation of trachea and, therefore, the more common site of foreign body enlodgement according to these authors probably applies to adults. Gyebre, Y. et al. [19] report that the laryngeal foreign bodies are common and grave, and the most common presentation is dyspnoea with dysphagia in the previously healthy children. Most of the complications (89.48\%) associated with foreign body removal in children with rigid broncho- 
scopy in the present series of patients were related to the operative and post operative hypoxaemia. Other complications were rare and included surgical emphysema of the neck and chest in one patient (5.26\%) and paralytic ileus in one (5.26\%). Mortality rate due to the rigid tube endoscopic extraction of foreign bodies in the present study was $8 \%$ which is higher than the many other reported series viz., Mahyarand Tarlan 2008-0.9\%, Mohammad Shafi et al. 2012-6\%, and, Abdulaziz O. A. et al. $2014-2.70 \%$ to $8.30 \%$ in various hospital studies. However, Cunanan [20] found a much higher mortality rate (12\%) using a rigid system compared to $1 \%$ using flexible fibre optic bronchoscopy. Certain risk factors that lead to hypoxaemic complications and mortality during endoscopic extraction of foreign bodies in the present series of patients were identified and included a vegetable foreign body necessitating a prolonged bronchoscopy beyond 20 minutes in patients below 3 years of age especially the infants, improper size and positioning of a bronchoscope, a semi-blind procedure without using a telescope or telescopic forceps, inadequate patient preparation and a lighter plane of anaesthesia, late presentation or delayed referral, failure to resuscitate a hypoxic patient during anaesthesia, inadequate knowledge about the bronchopulmonary anatomy, failure to recognize and manage a complication such as pneumothorax during or after bronchoscopy, and a less-skilled anaesthetist/bronchoscopist. Harboyen and Nassif [21] reported 36 instances (16\%) of tracheostomy in 225 bronchoscopies, mostly in the prolonged traumatic procedures. Bittencourt et al. [22] analysed the variables associated with hypoxaemia in children who underwent rigid bronchoscopy for foreign body removal. Among the patients aged up to one year the risk of hypoxaemia was five and half times higher than for patients aged one year or older $(O R=5.6)$. Furthermore, for each additional minute in the duration of the procedure the risk of hypoxaemia reached $4 \%(\mathrm{OR}=1.04)$. Chen $\mathrm{L}$. H. et al. [23] identified risk factors associated with intraoperative or with postoperative hypoxaemia in rigid bronchoscopy for foreign body extraction in children and conclude that five factors strongly correlated with intraoperative hypoxaemia: younger age, plant seed as the type of foreign body, longer operative duration, pneumonia before the procedure and spontaneous ventilation mode; and these factors significantly increased the risk of intraoperative hypoxaemia, whereas manual jet ventilation mode decreased it. Two factors were associated with postoperative hypoxaemia: plant seed as a foreign body and prolonged duration of emergence from anaesthesia. Jennis Dannilidis et al. (1977) suggest that special attention is needed in cases with vegetable foreign body inhalation which due to bronchial secretions increase in size, become soft and are easily broken to pieces on handling them with instruments and can get dispersed as small pieces in distal bronchi. Moreover, the vegetable foreign bodies induce intense inflammation in the tracheobronchial tree. According to Ross and McCormick [24], dry vegetable foreign bodies, for example a bean, cause very rapid obstructive changes due to a combination of mucosal irritation and the swelling of the bean itself by hygroscopic action. Atelectasis of the occluded segment of lung occurs with utmost rapidity 
in this type of foreign body. Limper et al. [25] noted $60.87 \%$ successful retrievals with the flexible, and $97.73 \%$ with the rigid bronchoscope. Nadir Saki et al. [26] in their 20 year experience with the management of aspirated foreign bodies in infancy comment that bronchoscopy in children under 12 months requires skill because technical difficulties due to small instrumentation and brochospasm commonly occur when compared to older children. They suggest that a bronchoscope of appropriate diameter should be chosen and the procedure should ideally be limited to 20 minutes in order to avoid subglottic oedema and bronchospasm due to bronchoscopy. Christian W. Fidkowski et al. (2010) in their review of large series of paediatric bronchoscopies for extracting aspirated foreign bodies report mortality due to rigid bronchoscopy as $0.42 \%$. While asphyxia at presentation or initial bronchoscopy causes some deaths, hypoxic cardiac arrest during retrieval of the object, bronchial and unspecified intraoperative complications in previously stable patients constitute the majority of in-hospital fatalities. Major complications include severe laryngeal oedema, bronchospasm requiring tracheostomy or reintubation, pneumothorax, pneumomediastinum, cardiac arrest, tracheal or bronchial laceration and hypoxic brain damage. Although several anaesthetic techniques are effective for managing children with foreign body aspiration, there isno consensus according to these authors from the literature as to which technique is optimal. T. Vittal Mohan et al. [27] in a retospective study of 108 cases of tracheobronchial foreign bodies recommend the use of proper instrumentation, thorough training and teamwork to be the key to achieve goal of zero mortality and no major complications in removing the inhaled foreign bodies. Brkic F. et al. [28] suggest the health care education to be the key to prevention of foreign body inhalation. Abdulazeez Omeza Ahmad and IliyasuYunusa Shuiabu (2014) advocate strong legislature to be put in place to regulate the sweet or toy producing companies on whistles (toys) manufactured with candies, and if possible these be totally withdrawn from the market. Besides, the parents have a fundamental role to play by providing constant supervision to children particularly in the infants H. Chew and H. Tan [29] suggest a high clinical suspicion and prevention to be the key factors in the management of inhaled foreign bodies in children. Mohammad Shafi et al. (2012) comment that delay in the diagnosis of foreign body inhalation translates into a higher risk of complications and suggest early bronchoscopy to be done on the suspicion of an inhaled foreign body. According to these authors the causes of mortality related brochoscopic extraction of foreign body include delayed bronchoscopy, and lack of expertise on the part of surgeon and the anaesthetist. Prolonged presence of foreign body in the airway can lead to irreversible changes in the lung with increased morbidity and mortality. Deaths due to bronchoscopy in their study occurred due to severe acute respiratory distress with cyanosis and attendant cerebral anoxia; and one due to profuse haemorrhage from granulations around an impacted foreign body.

Anissa Berraies et al. (2015) while admitting rigid bronchoscopy to be a gold standard for the inhaled foreign body extraction comment that there is an in- 
creased role of flexible fibre-optic bronchoscopy in the treatment of inhaled foreign bodies in children for whom the diagnosis of foreign body aspiration is doubtful. They recommend performing a flexible endoscopy in all children with suspected foreign body aspiration, except those with respiratory distress or a radio-opaque foreign body. First, according to these authors, it will avoid unnecessary rigid bronchoscopy in children without foreign body, or with foreign body that is located in distil bronchus and is, therefore, difficult to remove using a rigid bronchoscope. Secondly, it will localise the foreign body and thus guide the bronchoscopist. In their experience, flexible bronchoscope was used for foreign body removal in cases where the ENT specialist had not seen the foreign body because it was distil, or when attempt to remove the foreign body by rigid bronchoscopy failed. Flexible bronchoscopy was not attempted by these authors for proximal foreign bodies, friable foreign bodies and when it can become blocked in the larynx.

Rodriguez $\mathrm{H}$ et al. [30] report the technique of choice for removing aspirated foreign bodies is rigid bronchoscopy. The indication for flexible bronchoscopy according to these authors is primarily the verification of an uncertain diagnosis, or for its combination with rigid method, or the recovery of very small distally situated foreign bodies, and should not in principle be used as the primary technique for removal of all foreign bodies. Therefore, switching to the rigid technique should be possible at any time.

Remedial measures to reduce morbidity and mortality and thus improve prognosis in the endoscopic extraction of the inhaled foreign bodies are summarised as below:

- Incidence of foreign body inhalation can be significantly decreased if public awareness about not keeping extraneous material accessible to young children is increased. Parents have fundamental role in providing constant supervision to children especially in their infancy. Children have a natural tendency to explore foreign material and often put it in mouth and can inhale it especially as their swallowing mechanism is also not mature and coordinated. Moreover, it is suggested, toys such as plastic whistles manufactured with the candies to allure children be totally withdrawn from the market.

- Early suspicion of foreign body inhalation and early referral to the endoscopist by the paediatricians, chest physicians or the general practitioners to whom the patient may initially present is highly emphasised on the basis of the present study because bronchoscopy on a child with pre-existing pneumonitis due to a neglected foreign body was observed to increase the risk of intraoperative hypoxaemia. Besides, delay in diagnosis of foreign body inhalation and its extraction can lead to irreversible changes in the lungs with increased morbidity and mortality.

- Review of literature on the management of suspected foreign body aspiration in children shows virtual bronchoscopy being done with a multidetector C.T. Scanner in 3D image generation from axial cuts of the internal walls of the 
tracheobroncheal tree which can indicate exact location of the foreign body and even preclude the need to submit patient to rigid bronchoscopy in the absence of a foreign body. Flexible fibre optic bronchoscopy has also been recommended with the same purpose (Anissa Barraies et al. 2015) in the management of suspected foreign body inhalation in all children except those with respiratory distress or a radio-opaque foreign body. Flexible bronchoscopy will avoid unnecessaryrigid bronchoscopy in children without foreign body or with a foreign body which is located in distil bronchus. Besides, fibre-optic bronchoscope will localize the foreign body and so guide the subsequent rigid tube endoscopy when indicated.

- The endoscopist must have thorough knowledge about the brocho-pulmonary anatomy at different ages of an individual.

- In the present study use of $10 \%$ lignocaine spray into the laryngeal interior shortly before introducing the bronchoscope was observed to lessen the incidence of reflex bradycardia and cardiac arrest dramatically. Atropine is also routinely given to the patients before induction of anaesthesia for bronchoscopy and also during bronchoscopy for the treatment of bradycardia. Succinylcholine given in a controlled dosage fashion during anaesthesia prevents laryngospasm. Besides, jet ventilation mode of anaesthesia for extraction of the inhaled foreign body has been reported to decrease the intraoperative hypoxaemia whereas the spontaneous mode increases it (Chen L. H. et al. 2009).

- The present study showed a vegetable foreign body such as a bean, groundnut or pea as a significant cause for complications due to bronchoscopic extraction (14\%) as it often breaks down into multiple pieces during removal and may need several attempts at complete removal. Bronchoscopy on a younger child especially with history of a vegetable foreign body inhalation should not be attempted by a less skilled bronchoscopist/anaesthetist.

- Bronchoscopy should not be unnecessarily prolonged beyond about 20 minutes as it leads to bronchospasm and subglottic oedema and ultimately to complicated patient recovery due to hypoxaemia. The endoscope should be correctly positioned within the bronchus to aeriate the opposite lung. It must be of the proper size with respect to the age of the patient. It may have to be withdrawn to trachea during hypoxia for adequate ventilation before proceeding further, or alternatively may have to be withdrawn fully and the patient intubated and ventilated before the next attempt at bronchoscopy.

- Foreign bodies can be removed from the airway with speed and safety with telescopic optical forceps passed through the ventilating bronchoscope as these provide good visual control in locating the foreign body and its extraction.

- Falling oxygen saturation during or in the post operative period should be seriously taken notice of and managed effectively. Close co-operation between the endoscopist and the anaesthetist is mandatory. Similarly, other complications associated with bronchoscopy such as laryngospasm, pneumthorax and 
pneumonitis should be recognised and treated early enough.

\section{Conflicts of Interest}

The authors declare no conflicts of interest regarding the publication of this paper.

\section{References}

[1] Shehata, M.A. (1981) History of Laryngeal Intubation. Middle East Journal of Anaesthesia, 6, 49-55.

[2] Bradley, P.J. (1987) The Obstructed Airway. Scott-Brown's Otolaryngology, 5th Edition, 155-156.

[3] Veras, T.N., Hornburg, G., Schner, A.M.S. and Pinto, L.A (2009) Use of Virtual Bronchoscopy in Children with Suspected Foreign Body Aspiration. J. Bras. Pneumol., 35, 937-41. https://www.ncbi.nim.nih.gov>pubmed

[4] Aytac, A., Yurdakul, Y., Ikizler, C., Olga, R. and Saylam, A. (1976) Inhalation of Foreign Bodies in Children: Report of 500 Cases. The Journal of Thoracic and Cardiovascular Surgery, 74, 145-151.

[5] Mahyar, A. and Tarlan, S. (2008) Foreign Bodies Aspiration in Children. Acta Medica Iranica, 46, 115-119

[6] Kaur, K., Sonkhya, N. and Bopna, A.S. (2002) Foreign Bodies in the Tracheobronchial Tree: A Prospective Study of Fifty Cases. Indian Journal of Otolaryngology, Head and Neck Surgery, 54, 29-34.

[7] Shafi, M., Suhail, Z., Ashrafi, S.K.A. and Sajjad, S.M.Q. 2012) Frequency of Tracheobronchial Foreign Bodies and Their Management in Urban Population of Sindh. Journal of Pakistan Medical Association, 62, 896-899.

[8] Abdulaziz, O.A. and Iliyasu, Y.S. (2014) Inhaled Foreign Bodies in a Paediatric Population at AKTH Kano-Nigeria. Nigerian Medical Journal, 55, 77-82. https://doi.org/10.4103/0300-1652.128178

[9] Elhassani, N.B. (1978) Aspirated Tracheobronchial Foreign Bodies in Infants: An Analysis of 50 Cases. Journal of the Royal College of Surgeons of Edinburgh, 23, 310-314.

[10] Rothman, B.F. and Boeckman, C.R. (1980) Foreign Bodies in the Larynx and Tracheobrnchial Tree in Children. A Review of 325 Cases. Annals of Otology, Rhinology \& Laryngology, 89, 433-436.

[11] O’Neill, J.A., Holcomb, G.W. and Neblett, W.W. (1983) Management of Tracheobronchial Foreign Bodies in Childhood. Journal of Paediatric Surgery, 18, 475-479. https://doi.org/10.1016/S0022-3468(83)80204-8

[12] Berraies, A., Snen, H., Hamdi, B., Ammar, J., Mestiri, T., Kilani, T. and Hamzoui, A. (2015) Foreign Body Inhalation in Tunisian Children: Experience of a Paediatric Respiratory Diseases Department. Advances in Paediatric Research, 2, 17.

[13] Asif, M. Shah, S.A., Khan, F. and Ghani, R. (2007) Analysis of Tracheobronchial Foreign Bodies with Respect to Sex, Age, Type and Presentation. Journal of Ayub Medical College Abbottabad, 19, 13-16.

[14] Dennilidis, J., Symeonidis, B., Triaridis, K. and Kouloulas, A. (1977) Foreign Body in the Airways: A Review of 90 Cases. Archives of Otolaryngology, 103, 570-573. https://doi.org/10.1001/archotol.1977.00780270038002

[15] Senkaya, I., Sagdic, K., Gebitekin, C., Yilmaz, M., Ozkan, H. and Cengiz, M. (1997) Management of Foreign Body Aspiration in Infancy and Childhood: A Life Threat- 
ening Problem. Turkish Journal of Paediatrics, 39, 353-362.

[16] Fidkowski, C.W., Zhang, H. and Firth, P.G. (2010) The Anesthetic Considerations of Tracheobronchial Foreign Bodies in Children: A Literature Review of 12,979 Cases. Anesthesia \& Analgesia, 111, 1016-1025. https://doi.org/10.1213/ANE.0b013e3181ef3e9c

[17] Pinto, A., Scaglione, M., Pinto, F., Guidi, G., Pepe, M., Del Prato, B., Grassi, R. and Romano, L. (2006) Tracheobronchial Aspiration of Foreign Bodies: Current Indications for Emergency Plain Chest Radiograph. La Radiologia Medica, 1112, 497-506. https://doi.org/10.1007/s11547-006-0045-0

[18] Keith, F.M., Charrette, E.J.P., Lynn, R.B. and Salerno, T.A. (1980) Inhalation of Foreign Bodies by Children: A Continuing Challenge in Management. Canadian Medical Association Journal, 122, 52-57.

[19] Gyebre, Y., Zaghre, N., Goueta, A., Quattara, M. and Ouoba, K. (2016) Foreign Body Larynx in ORL Department of University Hospital-Yalgado Quedraogo. International Journal of Otolaryngology and Head \& Neck Surgery, 5, 129-133. https://doi.org/10.4236/ijohns.2016.53022

[20] Cunanan, O.S. (1978) The Flexible Fibreoptic Bronchoscope in Foreign Body Removal: Experience in 300 Cases. Chest, 73, 725-726.

[21] Harboyan, G. and Nassif, R. (1970) Tracheobronchial Foreign Bodies: A Review of 14 Years' Experience. The Journal of Laryngology \& Otology, 84, 403. https://doi.org/10.1017/S0022215100072017

[22] Bittencourt, P.F., Camargos, P. and Picinin, I.F. (2013) Risk Factors Associated with Hypoxaemia during Foreign Body Removal from Airways in Childhood. International Journal of Pediatric Otorhinolaryngology, 77, 986-989. https://doi.org/10.1016/j.ijporl.2013.03.026

[23] Chen, L.H., Zhang, X., Li, S.Q., Liu, Y.Q., Zhang, T.V. and Wu, J.Z. (2009) The Risk Factors for Hypoxaemia in Children Younger than 5 Years Undergoing Rigid Bronchoscoy for Foreign Body Removal. Anesthesia \& Analgesia, 109, 1079-1084. https://doi.org/10.1213/ane.0b013e3181b12cb5

[24] Ross, A.H. and McCormick, R.J. (1980) Foreign Body Inhalation. Journal of the Royal College of Surgeons of Edinberg, 25, 104-109.

[25] Limper, A.H. and Prakash, U.B.S. (1990) Tracheobronchial Foreign Bodies in Adults. Annals of Internal Medicine, 112, 604-609. https://doi.org/10.7326/0003-4819-112-8-604

[26] Saki, N., Nikakhlag, S., Rahim, F. and Abshirini, H. (2009) Foreign Body Aspiration in Infancy: A 20 Year Experience. International Journal of Medical Sciences, 6, 322-328. https://doi.org/10.7150/ijms.6.322

[27] Vittal Mohan, T., Sivakumar, S., Srinivas, R. and Balaji, S. (2015) Removal of Foreign Bodies in Paeditric Airway-Our Experience. IOSR Journal of Dental and Medical Sciences, 14, 26-29.

[28] Brkic, F., Delibegovic-Dedic and Hajderovic, D. (2001) Bronchogenic Removal of Foreign Bodies from Children in Bosnia and Herzegovina: Experience with $230 \mathrm{~Pa}$ tients. International Journal of Pediatric Otorhinolaryngology, 60, 193-196. https://doi.org/10.1016/S0165-5876(01)00531-6

[29] Chew, H. and Tan, H. (2012) Airway Foreign Body in Children. International Journal of Clinical Medicine, 3, 655-660. https://doi.org/10.4236/ijcm.2012.37117

[30] Rodriguez, H., Passali, G.C., Gregori, D., et al. (2012) Management of Foreign Bodies in the Airway and Oesophagus. International Journal of Pediatric Otorhinolaryngology, 76, 884-891. https://doi.org/10.1016/j.ijporl.2012.02.010 